\title{
Household food insecurity in the Islamic Republic of Iran: a systematic review and meta-analysis
}

\author{
F. Mohammadi-Nasrabadi, ${ }^{1}$ N. Omidvar, ${ }^{2}$ M.R. Khoshfetrat ${ }^{7}$ and F. Kolahdooz ${ }^{3}$
}

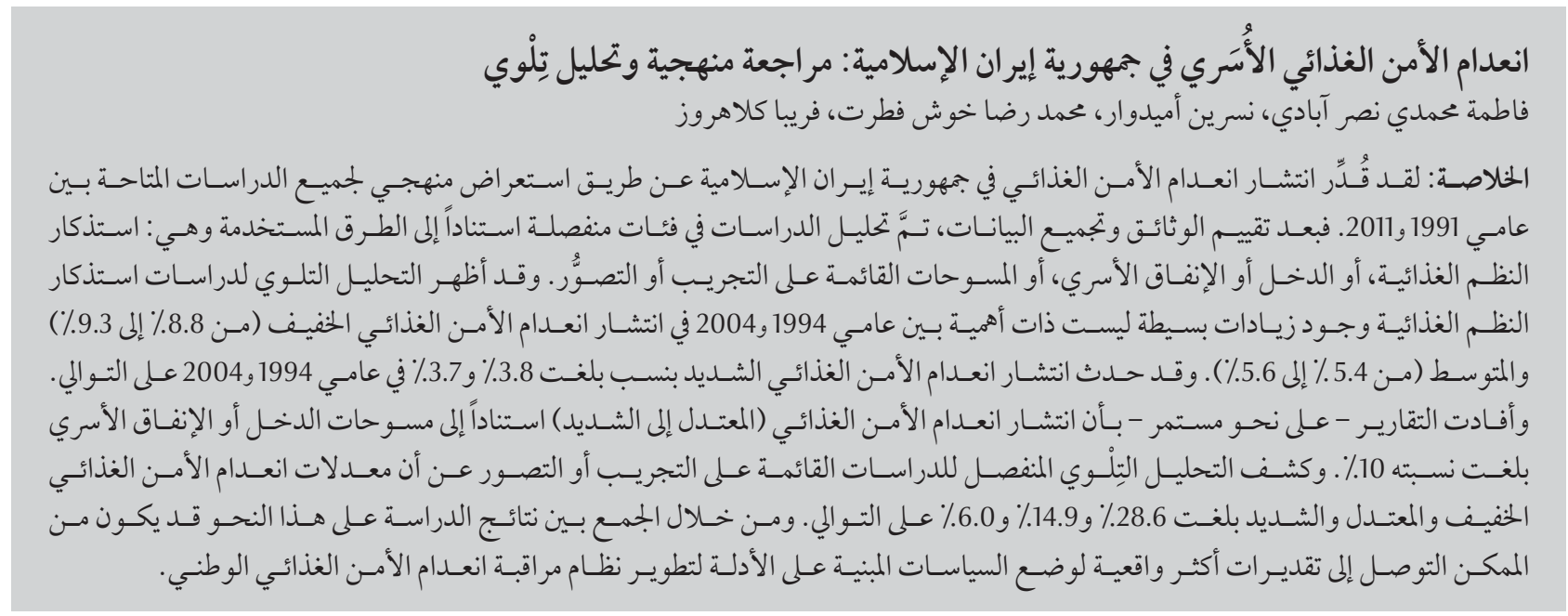

ABSTRACT Using a systematic review of all available studies between 1991 and 2011, the prevalence of food insecurity in the Islamic Republic of Iran was estimated. After document evaluation and data aggregation, studies were analysed in separate categories based on the methods used: dietary recall, household income/expenditure or experiential/ perception-based surveys. Meta-analysis of dietary-recall studies showed small non-significant increases between 1994 and 2004 in the prevalence of mild (from 8.8\% to 9.3\%) and moderate food insecurity (from 5.4\% to 5.6\%). Severe food insecurity was $3.8 \%$ and $3.7 \%$ in 1994 and 2004 respectively. Prevalence of food insecurity (moderate to severe) based on household income/expenditure surveys was consistently reported to be $10 \%$. A separate meta-analysis of experiential/perception-based studies revealed rates of mild, moderate and severe food insecurity of $28.6 \%, 14.9 \%$ and $6.0 \%$ respectively. By combining study results in this manner makes it possible to come up with more realistic estimates for evidence-informed policy-making, until development of a national food insecurity surveillance system.

\section{Insécurité alimentaire des ménages en République islamique d'Iran : revue systématique et méta-analyse}

RÉSUMÉ Une revue systématique de toutes les études disponibles entre 1991 et 2011 a permis d'estimer la prévalence de l'insécurité alimentaire en République islamique d'Iran. Après évaluation documentaire et agrégation des données, les études ont été analysées dans des catégories distinctes en fonction des méthodes appliquées : rappel de l'alimentation, revenu/dépenses par ménage ou enquêtes fondées sur l'expérience/la perception. La méta-analyse des études de rappel de l'alimentation a mis en évidence de faibles augmentations non significatives entre 1994 et 2004 de la prévalence de l'insécurité alimentaire légère (de 8,8 \% à 9,3\%) et modérée (de 5,4 \% à 5,6 \%). L'insécurité alimentaire sévère était de 3,8 \% et 3,7 \% en 1994 et 2004 respectivement. La prévalence de l'insécurité alimentaire (modérée à sévère) estimée à partir des enquêtes de revenu/dépenses des ménages a été rapportée de manière constante à $10 \%$. Une méta-analyse distincte des études fondées sur l'expérience/la perception a révélé des pourcentages d'insécurité alimentaire légère, modérée et sévère de 28,6 \%, 14,9\% et 6,0\%, respectivement. En associant les résultats d'étude de cette façon, il est possible de parvenir à des estimations plus réalistes pour alimenter des politiques fondées sur des preuves, en attendant d'avoir mis en place un système de surveillance de l'insécurité alimentaire au niveau national.

'Department of Food and Nutrition Policy and Planning Research, National Nutrition and Food Technology Research Institute, Faculty of Nutrition Sciences and Food Technology, Shahid Beheshti University of Medical Sciences, Tehran, Islamic Republic of Iran. ${ }^{2}$ Department of Community Nutrition, National Nutrition and Food Technology Research Institute, Faculty of Nutrition Sciences and Food Technology, Shahid Beheshti University of Medical Sciences, Tehran, Islamic Republic of Iran (Correspondence to N. Omidvar: omidvar.nasrin@gmail.com). ${ }^{3}$ Aboriginal and Global Health Research Group, Department of Medicine, Faculty of Medicine and Dentistry, University of Alberta, Edmonton, Canada. 


\section{Introduction}

Food security exists when all people, at all times, have physical and economic access to sufficient, safe and nutritious food to meet their dietary needs and food preferences for an active and healthy life (1). Because of its complex and multidimensional nature, measuring food insecurity has been an ongoing challenge for both researchers and practitioners (2). However, information on the population's food insecurity is needed to develop policies and programmes, monitor changes and evaluate the impact of food and nutrition programmes (3).

Different methods have been introduced for the measurement and screening of food security. Food consumption and expenditure surveys are the 2 most preferred methods that can provide more comprehensive and reliable information. However, such surveys are time-consuming, expensive and need highly qualified interviewers, and as a result they lack practicality in the field $(3,4)$. Recently, substantial effort has been directed to the development of alternative methods for measuring food insecurity in developing countries $(2,3)$. So-called "experiential" or "perception-based" methods of food insecurity measurement, developed by Radimer et al. (5), are based on the idea that people's experience of food insecurity (access) causes predictable reactions and responses that can be captured and quantified through a survey and summarized on a scale (5). Some of the tools developed from this approach have been used by the United States Department of Agriculture (USDA) since 1995 to monitor food assistance programmes and estimate the prevalence of food insecurity in the United States (US). The Household Food Security Survey Module (HFSSM) has consistently been validated as a statistically reliable and meaningful measure of food insecurity in the US (6). The Household Food Insecurity
Access Scale (HFIAS), an adaptation of HFSSM, also was developed by the Food And Nutrition Technical Assistance project to explore the possibility of using this approach in a developing country context $(2,3)$.

Following the Millennium Declaration and adoption of the Millennium Development Goals (MDGs) for combating poverty, hunger, disease, illiteracy, environmental degradation and discrimination against women in 2000 , special attention has been directed toward food insecurity and its measurement in the Islamic Republic of Iran. Studies performed in the country during the 1990s, in line with most other countries, measured mainly food access, either by measuring adequacy of energy and nutrients from consumption surveys or by estimating the poverty line obtained from income-expenditure surveys. Since 2000, direct measurement of food insecurity through perception-based questionnaires was gradually included. Despite validation and adaptation of some food insecurity scales for this country, the lack of homogeneity in measurement tools has resulted in outdated knowledge regarding the prevalence of differing levels of food insecurity in the country.

This study aimed to estimate the overall prevalence of food insecurity in the Islamic Republic of Iran, and to compare the estimates from different methods, through a systematic review of all available studies in the country between 1991 and 2011. The findings should provide insights into the present situation of food insecurity in the Islamic Republic of Iran and can be used to inform and sensitize policy-makers about the issue.

\section{Methods}

\section{Study design}

This systematic review was conducted according to the Meta-analysis Of Observational Studies in Epidemiology
(MOOSE) guidelines for reviews of observational studies (7) and was approved by the ethics committee of the Iranian National Nutrition and Food Technology Research Institute. The review included observational studies using different study designs, published from January 1991 to September 2011.

\section{Selection of studies}

All studies regarding food insecurity in the Islamic Republic of Iran published in any language (Farsi or English) were searched using PubMed, IranMedex, SID (Scientific Information Database), ISI (Information Sciences Institute) database, INP Abstracts (Iran's Nutrition Publication Abstracts), IranDoc and Magiran. Searches used the following terms or keywords: "household food security", "household food insecurity" and "Iran". Additional studies (grey literature) were identified by searching the reference lists of identified articles, 2 series of the comprehensive Abstracts of the National Nutrition and Food Technology Research Institute, projects and theses from the Faculty of Nutrition and Food Technology in 1995-2001 (8) and 2002-2006 (9), and Nutrition Abstracts and Reviews of Iran (12 volumes) (10). Abstract books of all 11 Iranian Nutrition Congresses and other related congresses, including the Student Nutrition Congress (11), were reviewed, and dissertations of medical and non-medical universities were referred to.

Searching the papers, selecting them and checking the extracted data were undertaken independently by the first 2 authors (F.M. and N.O.). The abstracts of all identified studies were read to exclude those that were irrelevant. Studies were considered only if the samples were of Iranian urban or rural households. The full texts of the remaining articles were read to determine whether they met the inclusion criteria.

Publications that did not contain the required data for the systematic review (i.e. prevalence of food insecurity based 
on energy intake, food expenditure or individuals' experiences/perceptions) were excluded. Studies conducted on specific age, ethnic or income groups, and those with identical data sets were also excluded. The following information was extracted from the remained relevant studies: author(s), year of publication, place, sampling method and subjects, measuring tool(s), food security criteria and figures on prevalence of food insecurity. After document evaluation and data aggregation, the studies were analysed in separate categories based on the methods used: dietary recall, household income/expenditure or experiential/perceptionbased surveys.

\section{Studies selected and omitted}

In the literature search, 52 potentially relevant publications were identified from information banks and the grey literature. Through the screening process based on the defined criteria, 40 studies were excluded: 14 studies were excluded after reading the title and abstract; 8 studies did not include the necessary data for a systematic review (12-19) [for instance, 2 of them had used the short form of the USDA questionnaire, which does not differentiate levels of food insecurity $(13,14)]$; 1 study was done on a particular age group (adolescents) (20); 2 studies were done on a special group (Afghan refugees) $(21,22) ; 3$ studies were undertaken only on low-income households (23-25); and 12 studies used identical data sets (26-37).

Among the 12 remaining studies which met the study criteria, 5 presented national data on the prevalence of household food security in the country [ 2 were based on dietary intake $(38,39)$, while 3 used household income/expenditure data (40-42)] and 7 used data from representative samples from 6 cities, mainly in central Islamic Republic of Iran, and were based on individuals' experiences and perceptions of food insecurity (43-49).

\section{Analysis}

For the meta-analysis, the variation of food insecurity prevalence in each study was computed based on a binomial distribution formula. For meta-analysis of the experiential/perception-based studies, some studies reported food insecurity both with moderate and severe hunger and without hunger, according to US-HFSSM. Therefore, we considered moderate, severe and low food insecurity respectively. In the 2 comprehensive national Iranian studies on household food consumption and nutritional status used for meta-analysis, food insecurity was defined in 3 levels of daily energy intake as follow: mild ( $80 \%-90 \%$ of energy requirements), moderate $(70 \%-80 \%$ of energy requirements) and severe $(<70 \%$ of energy requirements).

Using aheterogeneitytest (Cochran Q), we found significant variations between the study findings. Hence, a random-effect model was used for the estimations. In order to minimize the random variation between point estimates of the studies, the findings from each study were adjusted using Bayesian analysis. In this adjustment, the overall point estimate based on the random-effect model was used as prior prevalence. After describing the findings in forest plots, the point estimates and their $95 \%$ confidence interval (CI) were computed accordingly. The chisquared test was used to test the difference in food insecurity prevalence between the 2 dietary-intake studies that were conducted 10 years apart. All the analyses were conducted using Stata, version 9.

\section{Results}

The characteristics of the 12 studies (38-49) which met the study criteria are summarized in Table 1.

The 3 studies based on household income/expenditure were not included in the meta-analysis due to low variation in their data on the prevalence of food insecurity, which was repeatedly reported to be $10 \%$ in both rural and urban areas. We therefore based the metaanalysis of the prevalence of household food insecurity in the Islamic Republic of Iran on the other 2 categories of studies-dietary recall-based and experience/perception-based-and these were analysed separately.

The prevalence of severe, moderate and mild household food insecurity based on household dietary intake were extracted from 2 rounds of the National Comprehensive Study on Household Food Consumption and Nutritional Status in the Islamic Republic of Iran. The studies used similar methodologies and were conducted 10 years apart, in 1991-1995 and 2001-2003. As they deployed a large sample size, their findings were not combined in the metaanalysis with other, smaller studies conducted only in 1 province or district. The meta-analyses of the dietary-recall studies showed that the prevalences of mild, moderate and severe food insecurity in 2004 were $9.3 \%$ (95\% CI: $8.0 \%-10.5 \%$ ), $5.6 \%$ (95\% CI: $4.2 \%-$ $6.9 \%$ ) and $3.7 \%$ (95\% CI: $2.7 \%-4.8 \%)$ respectively (Figure 1). In 1994 the prevalences of mild and moderate food insecurity were $8.5 \%$ (95\% CI: 7.3\%9.7\%) and 5.4\% (95\% CI: 4.5\%-6.3\%) respectively, and severe food insecurity was estimated at 3.8\% (95\% CI: $3.1 \%-4.5 \%)$. None of the differences between the 2 time periods, however, were statistically significant $(P=0.09)$.

The perception-based studies used either the methods of US-HFSSM or HFIAS to measure household food insecurity. The underlying approach for both scales is the same. The metaanalysis of the 7 experiential/perception-based studies conducted over the years 1991-2011 indicated that the estimated prevalences of mild and moderate food insecurity were $28.5 \%$ (95\% CI: $20.8 \%-36.1 \%$ ) and $14.9 \%$ (95\% CI: $8.8 \%-21.1 \%)$ respectively and of severe food insecurity was $6.0 \%$ (95\% CI: 


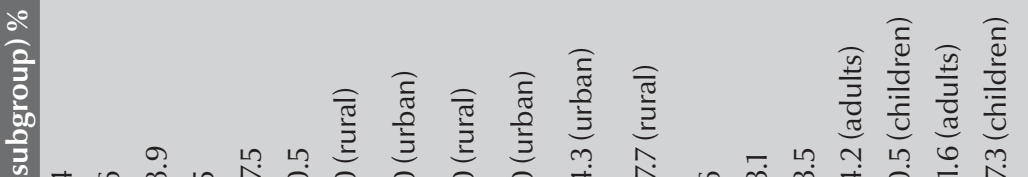

产 (n)

文
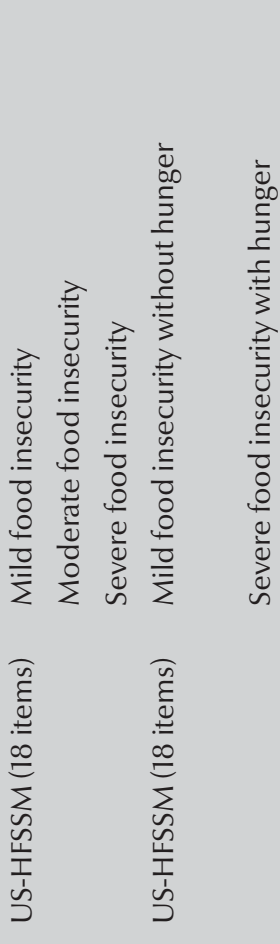

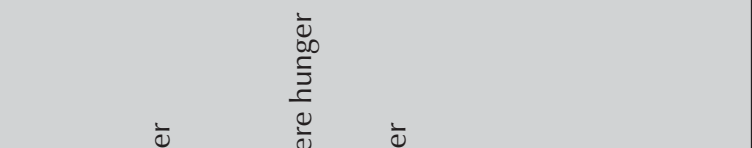

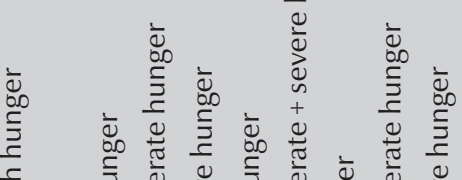

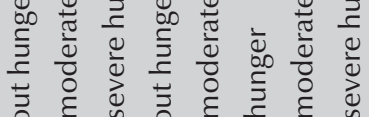

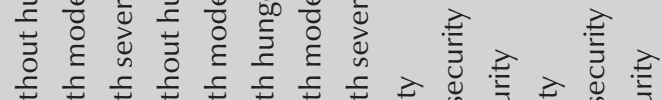

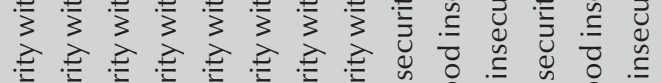

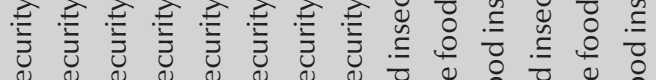

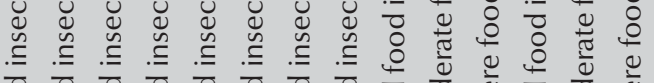

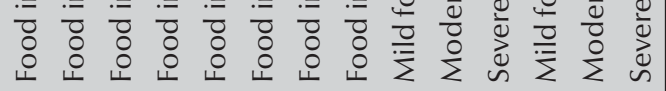

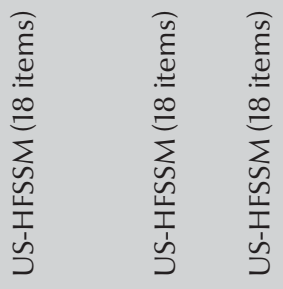

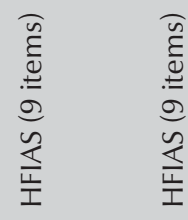

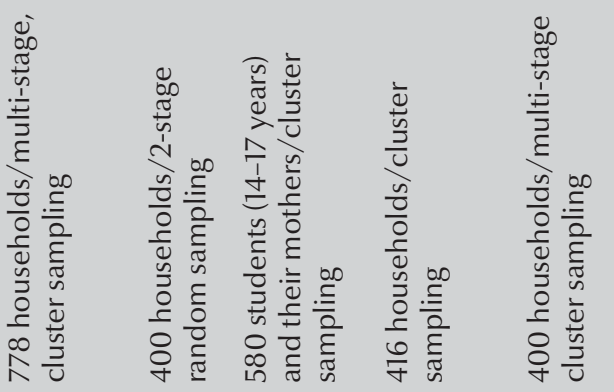

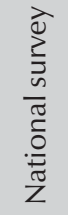




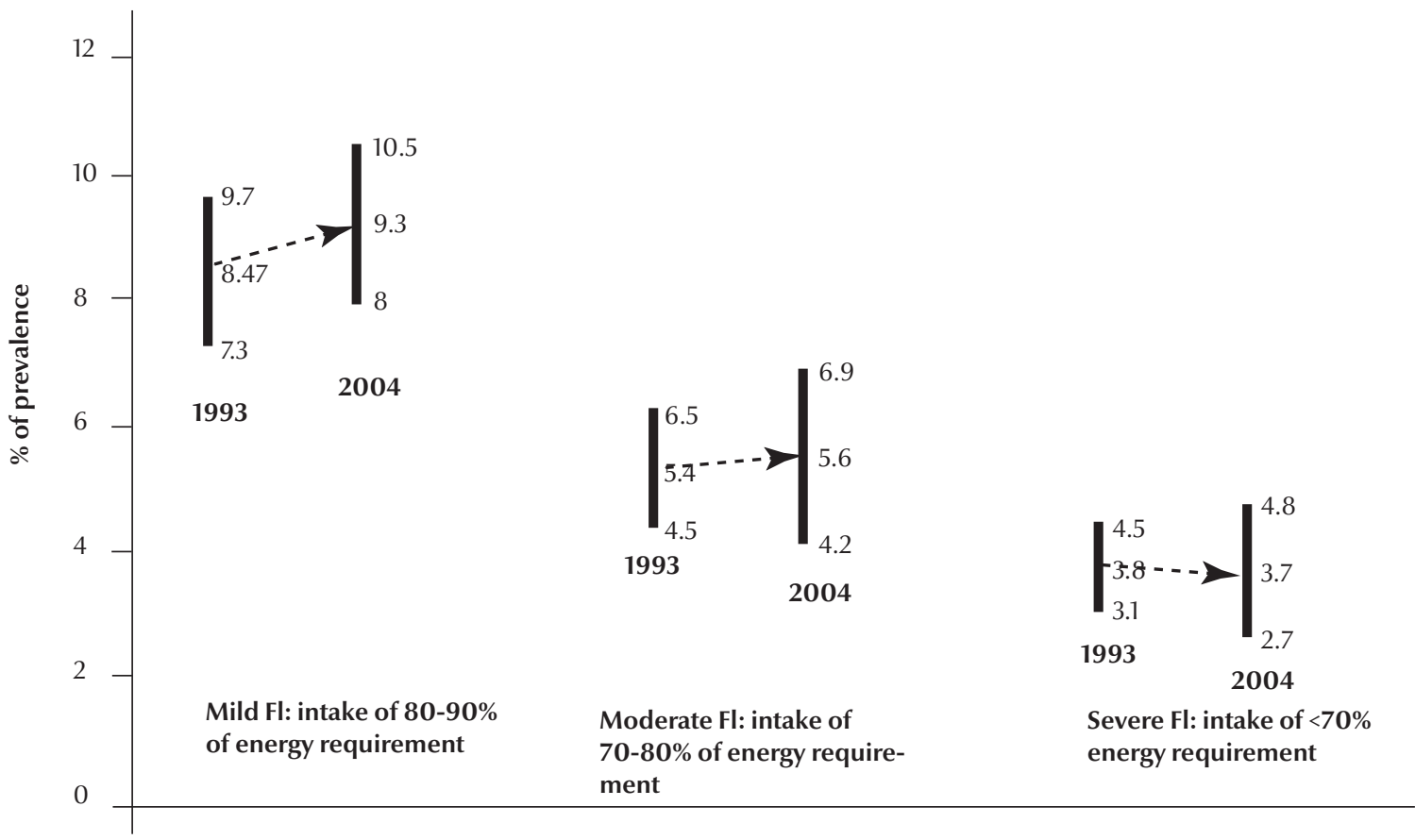

Figure 1 Prevalence (and 95\% confidence intervals) of household food insecurity (FI) in the Islamic Republic of Iran: metaanalysis of 2 rounds of national comprehensive studies on household food consumption and nutritional status (1993 and 2004$)$

$2.3 \%-9.8 \%)$ (Figure 2). A significant heterogeneity between the studies was detected $(P<0.001)$.

\section{Discussion}

The Islamic Republic of Iran is currently undergoing a nutrition transition leading to considerable variations in nutrition status within the population. As a result, low nutrient density characterizes diets at all income levels, over-consumption and obesity is evident among more than a third of the population, while food insecurity is also evident among a proportion of the Iranian population (50).

Our meta-analysis of the largescale, comprehensive national food consumption surveys in 1993 and 2004 showed rates of mild, moderate and severe food insecurity of $8.5 \%$, $5.4 \%$ and $3.8 \%$ respectively in 1994 and $9.3 \%, 5.6 \%$ and $3.7 \%$ respectively in 2004. These results also showed that the prevalences of mild and moderate food insecurity in the Islamic Republic of Iran increased slightly, but not significantly, between the 2 time periods, while a very slight decrease in severe food insecurity was discernible. These prevalences from the meta-analysis were lower than those presented by the original reports $(8.9 \%, 6.0 \%$ and $4.0 \%$ respectively in 1994 and $10.5 \%$, $7.5 \%$ and $5.5 \%$ respectively in 2004 ) $(38,39)$. However, the figures obtained from the meta-analysis are more accurate because of the use of weighting techniques and a heterogeneity test for estimating the overall prevalence.

The causes of food insecurity in the Iranian population were not investigated in our analysis. Based on previous studies in the Islamic Republic of Iran, however, season is not an issue with regards to food access in urban communities. Food insecurity in Iranian households is mainly affected by economic factors affecting food access and food price instability (34). Very few studies have been conducted in the Eastern Mediterranean Region using perception-based or recall-based methods. Therefore, a thorough comparison between our results and other countries in the Region is not possible. However, comparing the prevalence of food insecurity in the Islamic Republic of Iran with other types of data-based on food production per capita, the ratio between total export earnings and food imports, calories per capita and protein per capita, and nonagricultural population share-shows that our country ranks in the middle, while the highest levels of poverty and food insecurity were in Sudan, Yemen and Iraq (51).

From the meta-analysis of the perception-based studies the prevalences of food insecurity were 28.5\%, 14.9\% and $6.0 \%$ for mild, moderate and severe food insecurity respectively. These values are much higher than those of the recall-based national studies discussed above. This difference could be 


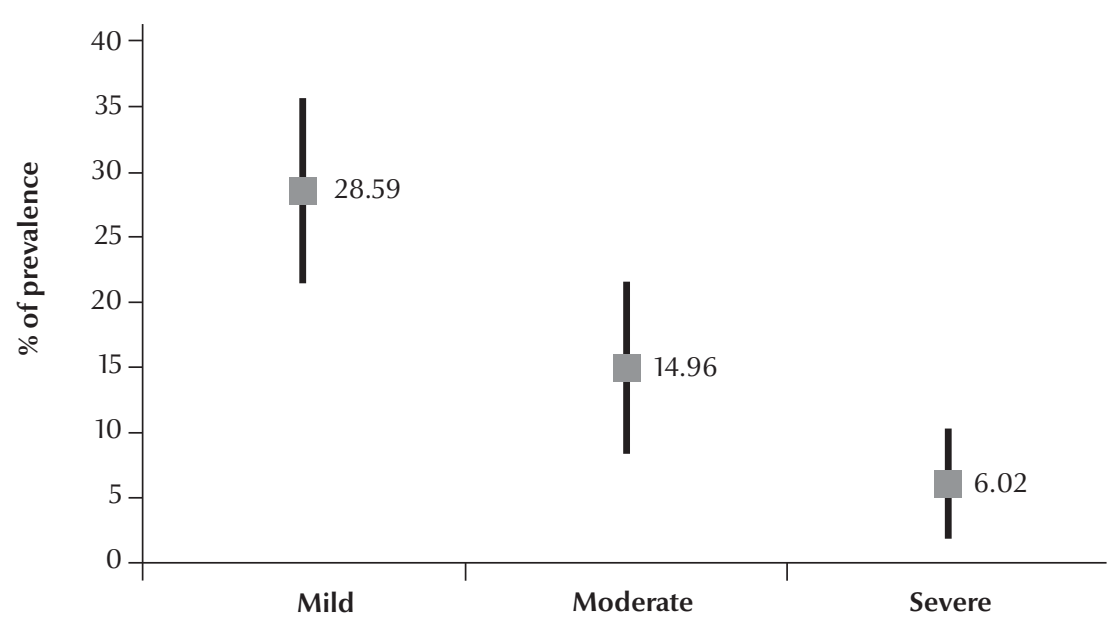

Figure 2 Prevalence (and 95\% confidence intervals) of mild, moderate and severe household food insecurity in the Islamic Republic of Iran: meta-analysis of 7 experiential/perception-based studies (1991-2011)

attributed to the nature of perceptionbased questionnaires, which measure attitudes and worries about food, whereas recall-based studies measure energy intake insufficiency as an outcome of food insecurity. The possibility of overestimation by participants in perception-based methods should also be taken into account. These rates are comparable with perception-based studies in countries having a similar level of development, for example Brazil, where the prevalences of mild, moderate and severe food insecurity were $23.1 \%, 9.7 \%$ and $4.7 \%$ respectively (52), but are lower than in poorer developing countries, such as Malawi, where the rates of moderate and severe food insecurity were $37.2 \%$ and $10.9 \%$ respectively (4). However, in Jordan, while the rate of food insecurity is similar to Islamic Republic of Iran when based on national figures on food availability and energy intake (51), perception-based data (in northern Jordan) showed a higher prevalence of food insecurity: $32.4 \%$ as a sum of moderate and severe food insecurity (53). As expected, the prevalence of food insecurity in developed countries (from perception-based studies) are much lower; for example in Canada (54) and the US (55), where moderate food insecurity rates were $8.9 \%$ and $5.1 \%$ respectively and severe food insecurity rates were $5.7 \%$ and $2.7 \%$ respectively. The reported prevalence of food insecurity were not fully comparable as the estimation of food insecurity in these studies was based on data from national surveys while the estimation of food insecurity prevalence in the Islamic Republic of Iran was based on a meta-analysis of experience/perception studies carried out only in certain provinces.

The perception-based studies included in this meta-analysis mainly used the methods of US-HFSSM or HFIAS to measure household food insecurity. The underlying approach for both scales is the same. However, the intended purpose and range of application for each tool is different. The HFSSM was developed exclusively for application in the US, while the HFIAS was developed to provide a cross-cultural equivalent measurement of food insecurity in resource-poor areas within a developing country setting. The relevance of each of these instruments for use in the Islamic Republic of Iran has not yet been investigated. However, other studies indicate that the choice of instrument for a particular population group may be important (56).
This study had some limitations. First, our meta-analysis included only information from 2 national recallbased and several local perceptionbased studies. There were 2 studies in the north-west of the country $(13,14)$ that were excluded due to lack of data on the different levels of food insecurity, as explained earlier. The perceptionbased studies included were conducted mainly in the central part of the Islamic Republic of Iran. No disaggregation of food insecurity data with regard to different provinces, climates and ethnic groups was available. In addition, generalizing the present data from experiential/perception studies beyond the urban population is limited due to the lack of data on rural areas. The number of households selected for the 2 large comprehensive food consumption surveys was limited in some regions; therefore, food insecurity prevalence in urban and rural areas could not be presented separately.

The present study is the first systematic review on food insecurity prevalence in the Islamic Republic of Iran. Due to the lack of a continuous food insecurity surveillance system in the country, there is a need for such approaches to support evidence-informed policy and to plan interventions to reduce food insecurity in different parts of the country. National food consumption surveys have been conducted every 10 years in the Islamic Republic of Iran and have provided valuable data for policy-making. However, because of the expense and time-consuming nature of food consumption surveys, it is recommended that one reliable perception-based method be applied over time at the national level to provide comparable data in shorter intervals. An ongoing project- the Implementation of Food Insecurity and Vulnerability Mapping System - in the Islamic Republic of Iran has the potential to provide the necessary data with geographical maps of food insecurity and vulnerability (57). 


\section{Acknowledgements}

The authors are grateful to the Director and personnel of the National Nutrition and Food Technology Research Institute. In addition, we thank those researchers who generated useful findings for our meta-analysis. We gratefully acknowledge Dr Hossein Ghassemi, Dr Heather Yeatman and Dr Deanne Condon-Paoloni for reviewing the manuscript and offering critical comments.
Funding: This work was funded by the National Nutrition and Food Technology Research Institute at Shahid Beheshti University of Medical Sciences [grant number $\mathrm{P} / 25 / 411 / 1824$ ].

Competing interests: None declared.

\section{References}

1. World Summit on Food Security. Rome, 16-18 November 2009. Rome: Food and Agriculture Organization; 1996 (WSFS 2009/2) (http://www.fao.org/fileadmin/templates/ wsfs/Summit/Docs/Final_Declaration/WSFS09_Declaration.pdf, accessed 10 August 2014).

2. Coates J, Swindale A, Bilinsky P. Household Food Insecurity Access Scale (HFIAS) for measurement of food access: indicator guide. Washington (DC): Food and Nutrition Technical Assistance Project; 2006 (http://www.fao.org/ fileadmin/user_upload/eufao-fsi4dm/doc-training/hfias. pdf, accessed 10 August 2014).

3. Deitchler M, Ballard T, Swindale A, Coates J. Validation of a measure of household hunger for cross-cultural use. Washington (DC): Food and Nutrition Technical Assistance II Project; 2010 (http://www.fantaproject.org/sites/default/ files/resources/HHS_Validation_Report_May2010_0.pdf, accessed 10 August 2014).

4. Deitchler M, Ballard T, Swindale A, Coates J. Introducing a simple measure of household hunger for cross-cultural use. Washington (DC): Food and Nutrition Technical Assistance; 2011 (http://www.fao.org/fileadmin/user_upload/ wa_workshop/docs/HH_Hunger_Scale.pdf, accessed 10 August 2014).

5. Radimer K, Olson C, Campbell C. Development of indicators to assess hunger. J Nutr. 1990;120:1544-8. PMID: 2243303.

6. Nord M, Andrews M, Carlson S. Household food security in the United States, 2007. Washington (DC): United States Department of Agriculture; 2008 (Economic Research Report Number 66) (http://www.ers.usda.gov/media/189567/ err66_reportsummary.pdf, accessed 10 August 2014).

7. Stroup DF, Berlin JA, Morton SC, Olkin I, Williamson GD, Rennie D, et al. Meta-analysis of observational studies in epidemiology: a proposal for reporting. Meta-analysis Of Observational Studies in Epidemiology (MOOSE) group. JAMA. 2000;283(15):2008-12. PMID: 10789670

8. Jamshidian-Tehrani $M$, editor. [The comprehensive abstracts of National Nutrition and Food Technology Research Institute (NNFTRI) projects and College of Nutrition and Food Technology theses (1995-2001)]. Tehran: National Nutrition and Food Technology Research Institute; 2002 [in Farsi].

9. HajMirsadeghi Z. Mohammadi M, Kamali Z, editors. [The comprehensive abstracts of projects and theses: National Nutrition and Food Technology Research Institute, Faculty of Nutrition Sciences and Food Technology (2002-2006)]. Tehran: National Nutrition and Food Technology Research Institute, Shahid Beheshti University of Medical Sciences; 2008 [in Farsi].

10. Aminpour $\mathrm{A}$, Omidvar $\mathrm{N}$, editors. [Nutrition abstracts and reviews of Iran]. Tehran: National Nutrition and Food Technology Research Institute; 1966-2005 [in Farsi].

11. Shokravi S, Dorosty A, editors. [National Congress of Nutrition Science Students, 2008]. Tehran: National Nutrition and Food Technology Research Institute; 2008 [in Farsi].
12. Samimi B, Djazayeri D, Siasi F, Mahmoodi M, Valaei N, Dorosti-Motlagh A. [Assessment of food consumption trends between 1983-1992 in Iran]. Tehran: Tehran University of Medical Sciences; 1995 [in Farsi].

13. Dastgiri S, Tutunchi H, Ostadrahimi A, Mahboob S. Sensitivity and specificity of a short questionnaire for food insecurity surveillance in Iran. Food Nutr Bull. 2007;28(1):55-8. PMID: 17718012

14. Sharafkhani R, Dastgiri S, Gharaaghaji R, Ghavamzadeh S, Didarloo A. The role of household structure on the prevalence of food insecurity. Eur J Gen Med. 2010;7(4):385-8.

15. Afshoon E, Malekzadeh J, Poormahmodi A. [Nutritional security in pattern of daily nutrients intake among households in Boyerahmad township in 1380-81]. 2 Armaghan Danesh (Journal of Yasuj University of Medical Sciences). 2003;31(8):59-68 [in Farsi]

16. Nemati A, Majidpour A, Saghgha M. [Assessment of food consumption pattern in rural population of Ardabil]. Research and Scientific Journal of Ardabil University of Medical Science and Health Services. 2003;2(8):51-8 [in Farsi].

17. Ostadrahimi A, Mahboob S, Totounchi H, Dastgiri S. [Prevalence and intensity of food insecurity (hunger and hidden hunger aspects) in Assadabadi region of Tabriz]. Yafteh (Journal of Lorestan University of Medical Sciences). 2006;1(8):61-6 [in Farsi].

18. Hoseinikhorrami S, Dastgiri S, Bakhtari F, Tutunchi H. Epidemiology of food insecurity in the North West of Iran. Res J Biol Sci. 2007;2:472-5.

19. Ghassemi H, Kimiagar M, Koupahi M. [Food and nutrition security in Tehran Province]. Tehran: National Nutrition and Food Technology Research Institute; 1996 [in Farsi].

20. Djazayeri A, Pourmoghim M, Omidvar N, Dorostimotlagh A. [Food security and nutrient intakes in a group of high school girls in Tehran, Iran]. Iran J Public Health. 1999;28(1-4):1-10 [in Farsi].

21. Sheykholeslam R, Abdollahi M, Abdollahi Z, Kalantari N, Salarkia N, Amini M, et al. [Food security assessment of urban afghan refugee populations in Pakdasht, Iran (2008)]. Tehran: National Nutrition and Food Technology Research Institute; 2009.

22. Omidvar N, Ghazi-Tabatabie M, Sadeghi R, Mohammadi F, Abbasi-Shavazi M. Food Insecurity and its sociodemographic determinants among Afghan immigrants in Iran. J Health Popul Nutr. 2013 Sep;31(3):356-66. PMID: 24288950

23. Ghazi-Tabatabaie M, Omidvar N, Ali-Hosseini J. [Sociodemographic determinants of food insecurity among vulnerable households in district 20, city of Tehran]. Quarterly Journal of Social Sciences. 2011;52:69-94 [in Farsi].

24. Zerafati-Shoae N, Omidvar N, Ghazi-Tabatabaie M, Rad AH, Fallah H, Mehrabi Y. Is the adapted Radimer/Cornell questionnaire valid to measure food insecurity of urban households in Tehran, Iran? Public Health Nutr. 2007;10(8):855-61. PMID: 17498320 
25. Payab M, Dorosty Motlagh AR, Eshraghian MR, Siassi, Karimi $\mathrm{T}$. The association between food insecurity, socio-economic factors and dietary intake in mothers having primary school children living in Ray 2010. Nutrition Sciences and Food Technology. 2012;7(1):75-84.

26. Dastgiri S, Mahboob S, Tutunchi H, Ostadrahimi A. [Determinants of food insecurity: a cross-sectional study in Tabriz] Journal of Ardabil University of Medical Sciences and Health Services. 2006;3(6):233-9 [in Farsi].

27. Ghassemi H. [Food and nutrition security in Iran: a national study on planning and administration]. Tehran: Plan and Budget Organization; 1998 [in Farsi].

28. Sharafkhani R, Dastgiri S, AsI RG, Ghavamzadeh S. Factors influencing household food security status. Food and Nutrition Sciences. 2011;2:31-4.

29. Houshiar-Rad A, Ghaffarpour M, Hormozdyari H. [Country proposed optimum food basket: preliminary studies and findings]. In: Aminpour A, Omidvar N, editors. [Nutrition abstracts and reviews of Iran (2001-2002)]. Tehran: National Nutrition and Food Technology Research Institute; 2003 [in Farsi].

30. Khodadad-Kashi F, Heydari K. [Estimation of food security level of Iranian households based on AHFSI]. Agricultural Economic and Development. 2004;12(48):155-72 [in Farsi].

31. Karam-Soltani Z, Dorosty-Motlagh A, Eshraghian M, Siassi F, Djazayeri A. [Obesity and food security in Yazd primary school students]. Tehran Univ Med J. 2007;7(65):68-76 [in Farsi].

32. Karam-Soltani Z. [Prevalence of obesity and household food insecurity in Yazd primary school]. Tehran: Tehran University of Medical Sciences; 2006 [in Farsi].

33. Mohammadi F, Omidvar N, Houshiar-Rad A, Mehrabi Y, Abdollahi M. [Association of food security and body weight status of adult members of Iranian households]. Nutrition Sciences and Food Technology. 2008;2(3):41-53 [in Farsi].

34. Mohammadi-Nasrabadi F. [Measurement and modeling of household food security in urban households in the city of Tehran] [PhD thesis]. Tehran: Faculty of Nutrition Sciences and Food Technology, Shahid Beheshti University of Medical Sciences; 2011 [in Farsi]

35. Mohammadzadeh A, Dorosty A, Eshraghian M. Association of food security and socio-economic status and body weight status of adolescents. Iranian Journal of Nutrition Sciences and Food Technology. 2010;5(1):55-69 [in Farsi].

36. Ramesh-Zarch T. [The prevalence of household food insecurity in urban areas of Shiraz and some associated factors, 1387] [MSc thesis]. Tehran: Faculty of Nutrition Sciences and Food Technology, Shahid Beheshti University of Medical Science and Health Services; 2009 [in Farsi].

37. Zerafati-Shoaa N. [Validation of Radimer Cornell modified questionnaire in food security assessment of urban households of Tehran's district 20] [MSc thesis]. Tehran: Faculty of Nutrition Sciences and Food Technology, Shahid Beheshti University of Medical Sciences; 2004 [in Farsi].

38. Kimiagar M et al. [National Comprehensive Study on Household Food Consumption Pattern and Nutritional Status in IR Iran, 1991-1995]. Tehran: Center of Agricultural Economic Studies and Planning, National Nutrition and Food Technology Research Institute; 1996 [in Farsi].

39. Kalantari N, Ghaffarpour M, HoushiarRad A, Abdollahi M, Kianfar H, Bondarianzadeh D. [National Comprehensive Study on Household Food Consumption Pattern and Nutritional Status in IR Iran, 2001-2003]. Tehran: Nutrition Research Department, National Nutrition and Food Technology Research Institute, Shaheed Beheshti University of Medical Sciences, Ministry of Health; 2005 [in Farsi].
40. Pajouyan J. [Comprehensive study on nutritional practise and food security of Iranian households]. Tehran: Commercial Studies and Researches Foundation; 2005 [in Farsi].

41. Heydari K. [Economic analysis of nutritional indices and food adequacy in Iran]. In: Mahboob S, editor. [Proceedings of the 9th Iranian Nutrition Congress, 4-7 September, Tabriz, Islamic Republic of Iran]. Tabriz: Tabriz University of Medical Sciences; 2006. p. 91-109 [in Farsi].

42. Jafari-Sani M, Bakhshoodeh M. [Assessment of food insecurity status in rural and urban parts of Iran]. In: Mahboob S, editor. [Proceedings of the 9th Iranian Nutrition Congress, 4-7 September, Tabriz, Islamic Republic of Iran]. Tabriz: Tabriz University of Medical Sciences; 2006. p. 269-80 [in Farsi].

43. Dorosty AR, Karamsoltani Z, Jazayeri A, Siassi F, Eshraghian M. [Association between obesity, food security and related family factors]. Journal of School of Public Health and Institute of Public Health Research. 2008;1(6):1-9 [In Farsi].

44. Rafiei M, Nord M, Sadeghizadeh A, Entezari MH. Assessing the internal validity of a household survey-based food security measure adapted for use in Iran. Nutr J. 2009;8:28-38. PMID:19558676

45. Ramesh T, Dorosty-Motlagh A, Abdollahi M. [Prevalence of household food insecurity in the city of Shiraz and its association with socio-economic and demographic factors, 2008]. Nutrition Sciences and Food Technology. 2010;4(4):53-64 [in Farsi].

46. Hakim S, Dorosty A, Eshraghian M. Association of food insecurity and household socio-economic status with the body mass index among urban women in Dezful. Journal of School of Public Health and Institute of Public Health Research. 2010;8(2):55-66 [in Farsi].

47. Mohammadzadeh A, Dorosty A, Eshraghian M. [Household food security status and associated factors among highschool students in Esfahan, Iran]. Public Health Nutr. 2010 Oct;13(10):1609-13. PMID: 20359375

48. Mohammadi F, Omidvar N, Houshiar-Rad A, Khoshfetrat M, Abdollahi M, Mehrabi Y. Validity of an adapted Household Food Insecurity Access Scale in urban households in Iran. Public Health Nutr. 2012 Jan;15(1):149-57. PMID: 21806860

49. Salarkia N, Abdollahi M, Amini M, Eslami-Amirabadi M. [Validation and use of the HFIAS questionnaire for measuring household food insecurity in Varamin-2009]. Int J Endocrinol Metab. 2011;13(4):374-83 [in Farsi].

50. Ghassemi H, Harrison G, Mohammad K. An accelerated nutrition transition in Iran. Public Health Nutr. 2002 Feb;5(1A):149-55. PMID: 12027278

51. Lofgren H, Richards A. Food security, poverty, and economic policy in the Middle East and North Africa. Washington (DC): International Food Policy Research Institute; 2003 (TMD Discussion Paper No. 111) (http://www.ifpri.org/sites/default/ files/publications/tmdp111.pdf, accessed 10 August 2014).

52. IBGE releases previously unseen profile of food security in Brazil. Brasilia: Instituto Brasileiro de Geografia e Estatística; 2006 [Internet] (http://saladeimprensa.ibge.gov.br/en/noti cias?idnoticia=600\&view=noticia, accessed 10 August 2014).

53. Bawadi HA, Tayyem RF, Amal N, Dwairy AN, Al-Akour N. Prevalence of food insecurity among women in Northern Jordan. J Health Popul Nutr. 2012;30(1):49-55. PMID: 22524119

54. Canada H. Household food insecurity in Canada in 20072008: Key statistics and graphics. Ottawa, Ontario: Health Canada; 2009 (http://www.hc-sc.gc.ca/fn-an/surveill/nutrition/commun/insecurit/key-stats-cles-2007-2008-eng. php, accessed 10 August 2014).

55. Nord M, Andrews M, Carlson S. Household food security in the United States, 2008. Washington (DC): United States Department of Agriculture, Economic Research Service; 2009. 
56. Holland AC, Kennedy MC, Hwang SW. The assessment of food security in homeless individuals: a comparison of the Food Security Survey Module and the Household Food Insecurity Access Scale. Public Health Nutr. 2011 Dec;14(12):22549. PMID:21740619
57. Delavar M. [The implementation of food insecurity and vulnerability mapping system in Iran]. Tehran: Ministry of Health; 2007 [in Farsi]. 